\title{
Revisão e enfoque clínico sobre a bacteriologia das infecções endodônticas agudas
}

\author{
Bacteriology of the acute endodontic infection: \\ Review of the literature and clinical approach
}

\author{
Simone Bonato Luisi* \\ Elaine Vianna Freitas Fachin**
}

\section{RESUMO}

O conhecimento mais aprofundado sobre a microbiologia endodôntica é um recurso fundamental para entender o papel das bactérias na origem e desenvolvimento dos processos patológicos apicais, bem como compreender a conseqüente resposta dos tecidos frente à infecção. Sendo assim, nosso objetivo ao revisar a literatura sobre microbiologia endodôntica é revelar quais bactérias estāo mais freqüentemente relacionadas aos canais radiculares necróticos e, por conseguinte, fornecer dados a serem usados para a escolha de métodos mais adequados para erradicar e controlar a infecçāo do canal radicular durante a terapia endodôntica.

\section{UNITERMOS}

Infecção Endodôntica, Bacteriologia Endodôntica, Infecção do Canal Radicular.

\section{INTRODUÇÄO}

As alteraçōes pulpares e periapicais apresentam uma etiologia direta ou indiretamente relacionada aos microrganismos. Isto foi demonstrado há mais de um século, quando em 1890, Miller ${ }^{26}$ evidenciou a presença de bactérias no canal radicular. Desde então, vários estudos ${ }^{40.7 .33 .42 .17 .5 .23 .27 .41 .13 .32 .19 .28 .31 .16 ~ t e ̂ m ~}$ demonstrado o importante papel da bactéria na patogênese dessas alteraçōes.

A infecção bacteriana é a causa mais comum das necroses pulpares. Ostrander e Crowley ${ }^{35}$ relataram que aproximadamente $80 \%$ das necroses pulpares, em humanos, é devido a cárie.

Um estudo clássico foi realizado por Kakehashi et al ${ }^{20}$. Esses autores expuseram a polpa dental de ratos convencionais e germ-free ao meio bucal. Nos ratos convencionais, houve o desenvolvimento de inflamação crônica e finalmente granulomas periapicais. Por outro Lado, em um ambiente livre de germes, a resposta aos tecidos pulpares expostos foi caracterizada por uma inflamação mínima e a formaçāo de pontes de dentina, evidenciando o papel fundamental das bactérias no desenvolvimento das lesões.

\section{ESTADO BACTERIOLÓGICODE DENTES NECRÓTICOS COM COROAS INTEGRAS}

Além da cárie dentária, a necrose pulpar também pode ser originada por um traumatismo, onde haja o rompimento do feixe vásculo-nervoso e conseqüente degeneração pulpar. Na atualidade, a bacteriologia dos canais radiculares de dentes necróticos, com coroas integras vem despertando o interesse de diversos pesquisadores. Tanto é assim que em 1957. MacDonald JB et al $^{24}$, investigando o estado bacteriológico de câmaras pulpares de 46 dentes intactos, não vitais e seguidos de trauma, obtiveram o crescimento bacteriano em 38 dentes. Diversos estudos ${ }^{18,6,14}$ foram feitos, sempre revelando a presença das bactérias nos dentes necróticos com coroas intactas.

Em 1976, Sundqvist ${ }^{17}$ também constatou a presença de microrganismos nos canais radiculares de dentes com polpas necróticas seguidas de trauma, corroborando o estudo anterior de MacDonald ${ }^{24}$.

\section{ORIGEM DA INFECÇÃO \\ ENDODÔNTICA EM DENTES COM COROAS ÍNTEGRAS}

Os caminhos através dos quais os microrganismos podem atingir a polpa são os vasos sangǘneos do periodonto ou da corrente sangüinea ou ambos ${ }^{18} \mathrm{~A}$ infecção do canal radicular também pode se originar por via circulação sangüínea durante uma bacteremia transitória, fenômeno este conhecido como anacorese e referendado por diversos autores 6.14 .29

Embora diversos estudos suportam esta teoria, Delivanis" et al constatou que as bactérias podem nāo ser recuperadas dos canais radiculares quando a corrente sangüínea foi experimentalmente infectada sem que haja uma sobre-instrumentação do canal radicular durante o período de bacteremia.

Além disso, os experimentos de Möller ${ }^{25}$ conclusivamente descartam a anacorese como um potencial para originar infecção pulpar. Isto devido uma pesquisa realizada em 26 macacos onde todos permaneceram estéreis e nécróticos por mais de 6 meses. A exposição pulpar à cavidade oral, diretamente, ou via canais acessórios, exposição dos túbulos dentinários ou micro faturas adjacentes ao sulco gengival ou na profundidade da bolsa periodontal são os mais prováveis caminhos da infecção endodôntica ${ }^{25}$.

Os estudos de Sundqvist ${ }^{17}$, foram de extrema valia para o conhecimento das infecçōes endodônticas, pois a partir daí os anaeróbios foram revelados como os principais microrganismos das patologias endodônticas.

\section{ANAERÓBIOS}

Em verdade, até 1970 , os estudos ${ }^{40.24}$ do ecossistema microbiano do canal radicular de dentes despulpados e infectados mostravam predominância de microrganismos aeróbios, sendo que as referências de anaeróbios estritos eram escassas em razão das dificuldades de isolamento dessas bactérias. Entretanto, com o advento dos métodos práticos para a cultura anaeróbia, tomou-se evidente, através de diversos estudos ${ }^{5,41,13,32,19,16}$, que há uma elevada prevalência de anaeróbios, nos canais radiculares necróticos.

Os maiores avanços na tecnologia anaeróbica foram: a) o uso de uma câmara de anaerobiose (caixa com luvas para anaerobiose), na qual a bactéria está protegida do oxigênio durante o isolamento e cultura; b) o desenvolvimento de meios de cultura préreduzidos, estéreis e anaeróbios ${ }^{8}$. Estas técnicas náo são apenas capazes de promover o isolamento e a caracterização dos anaeróbios obrigatórios dos canais radiculares infectados, mas também evitam o problema de contaminação durante a amostragem endodôntica ${ }^{10}$.

Walton e Torabinejad ${ }^{39}$ citam que das

\footnotetext{
- Mestranda em Odontologia pela F.O. UFRGS

Professora da Disciplina de Estágio Supervisionado II da FO-UFRGS

- Master of Science pela Universidade de Illinois, Chicago

Doutora em Endodontia pela F.O. USP-SP

Professora Adjunta das Disciplinas de Endodontia da F.O. UFRGS
}

R. Fac. Odontol., Porto Alegre, v. 40, n. I, p. 42-46, set. 1999 
mais de 350 espécies de bactérias reconhecidas como microbiota bucal normal, apenas um grupo relativamente pequeno é isolado das cavidades pulpares infectadas. Referem que, das bactérias isoladas, há um predomínio de anaeróbios estritos, anaeróbios facultativos e raramente aeróbios.

Apesar de diferenças na metodologia laboratorial, os autores ${ }^{33.22,17.5 .23 .411 .37 .34 .36 .38 .15 .4 .16 ~}$ têm evidenciado, há pouco mais de duas décadas, uma associação positiva entre a microbiota do canal radicular e os sintomas clínicos da necrose pulpar.

Em função dos inúmeros trabalhos científicos que tratam desse tema, decidiu-se dividir a revisão em 2 segmentos: $1^{\circ}$ ) trabalhos enfocando a microbiologia endodôntica de casos assintomáticos $\mathrm{e}, 2^{\circ}$ ) trabalhos enfocando a microbiologia de patologias endodônticas sintomáticas.

\section{CANAIS RADICULARES NECRÓTICOS ASSINTOMÁTICOS}

Thilo et $a^{35}$ através da microscopia de campo escuro, observaram a distribuição bacteriana nos terços coronário e apical dos canais radiculares de dentes que sofreram necrose pulpar. Após a exodontia, vinte dentes monorradiculares de 19 pacientes foram seccionados em três partes iguais. Os resultados demonstraram uma maior porcentagem de cocos e bacilos no terço coronário do que no terço apical. Os autores observaram uma positiva correlação entre a porcentagem de espiroquetas no terço apical e o tamanho da lesão visível radiograficamente.

Nair PNR ${ }^{27}$, realizou um estudo em 30 granulomas e 1 cisto radicular obtidos de dentes extraídos. Todos os 31 dentes apresentaram bactéria no interior do canal radicular. A flora endodôntica consistiu de uma mistura de cocos, bacilos, formas filamentosas e espiroquetas. Foi verificado que apenas uma fração pequena das lesões periapicais revelava bactérias dentro do corpo da lesão. Tais lesões eram invariavelmente agudas e sintomáticas.

Fukushima et al ${ }^{13}$ realizaram um estudo em 21 dentes portadores de patologia periapical assintomática. Os dentes foram extraídos para se examinar a localização e identificação da bactéria no canal radicular.

Em 60\% dos casos os autores encontraram culturas polimicrobianas. Os microrganismos que predominaram foram: Bacteroides, Peptococcus, Peptostreptococcus e Eubacterium, os quais também estão presentes nos casos sintomáticos. Esses dados permitiram aos autores concluir que as bactérias, persistindo no ápice das lesões assintomáticas, podem ter um potencial patológico para a progressão de patologias periapicais sintomáticas.

Sudqvist et al $^{32}$ investigaram as relações entre microrganismos dos canais radiculares de dentes com periodontite apical. As amostras foram feitas com pontas de papel absorventes em 65 canais radiculares de dentes humanos infectados, com evidência radiográfica de reabsorção óssea. As espécies mais comumente isoladas foram: Fusobacterium nucleatum, Prevotella intermedia, Peptostreptococcus micros, Peptostreptococcus anaerobios, Eubacterium alactolyticum, Eubacterium lentum e Wolinella recta. Associações positivas foram encontradas entre Fusobacterium nucleatum e Peptostreptococcus micros; Porphyromonas endodontalis, Selenomonas sputigena e Wolinella recta. Também foi positiva a associação entre Prevotella intermedia e Peptostreptococcus micros; Peptostreptococcus anaerobios e Eubacterium. Em geral, as espécies de Streptococcus, Propionibacterium propionica, Capnocytophaga ochracea e Veillonella parvula não demonstraram ou apresentaram associações negativas com outras bactérias. Os resultados são consistentes com o conceito de que um ambiente especial e seletivo ocorre no canal radicular devido, em parte, a natureza cooperativa e antagonista das relações entre bactéria e canal radicular.

Assed et $\mathrm{al}^{2}$ realizaram um estudo para avaliar a presença de microrganismos anaeróbios em canais radiculares de dentes humanos com periodontite apical crônica. Foram estudados 25 incisivos superiores centrais e laterais apresentando imagem radiográfica de periodontite apical crônica. A imunofluorescência indireta foi utilizada para detectar Actinomyces viscosos, Fusobacterium nucleatum, Porphyromonas gingivalis e Prevotella intermedia. Os resultados demonstraram uma positiva reação de imunofluorescência indireta em 24 das 25 amostras. Foram positivas 14 espécimes para a espécie Actinomyces viscosos, 12 para Prevotella intermedia, 10 para Fusobacterium nucleatum e 4 para Porphyromonas gingivalis.

\section{CANAIS}

\section{RADICULARES}

\section{NECRÓTICOS SINTOMÁTICOS}

Ainda na década de 70, os pesquisadores estudaram a microbiologia endodôntica, objetivando associar microrganismos específicos com os sintomas clínicos da necrose pulpar. Sundqvist $\mathrm{G}$ et $\mathrm{al}^{33}$ foram os pioneiros e já, naquela época, apresentaram o papel importante dos Bacteroides nos processos agudos periapicais. Os resultados encontrados pelos pesquisadores sugerem que a inflamação purulenta na região apical, em certos casos, pode ser induzida por combinações específicas de bactérias no canal radicular e que a presença do Bacteroides melaninogenicus ou Bacteroides asacharolyticus é essencial em tais combinações. Entretanto, com apenas uma exceção, as bactérias necessitaram de um suporte adicional de microrganismos para atingir a patogenia. Os resultados indicaram que o Peptostreptococcus micros também foi essencial.

Griffee $\mathrm{MB}$ et al ${ }^{17}$ procuraram verificar os achados de Sundqvist ${ }^{33}$ e estudaram a relação dos Bacteroides melaninogenicus com sintomas da necrose pulpar. Os autores concluíram que os anaeróbios são relevantes na patogênese de problemas endodônticos. O Bacteroides melaninogenicus é um patógeno importante no desenvolvimento dos sintomas comumente associados com necrose pulpar. Esse microrganismo é significativamente relacionado com o odor fétido, dor, formação de fístula e está provavelmente relacionado com edema e sensibilidade à digitação apical. Entretanto, não foi significante a relação entre a presença ou ausência de $B$. melaninogenicus e rarefação periapical, sensibilidade à percussão e presença de exsudato.

Estudos quantitativos da bacteriologia das infecções endodônticas também foram realizados paralelamente. Um exemplo é o estudo de Zavistoski et al $^{42}$, que encontraram anaeróbios em $64 \%$ de todas as espécies isoladas e em $90 \%$ dos casos uma flora mista de anaeróbios e aeróbios.

A bacteriologia de infecções piogênicas de origem dentária foi estudada em 1981 por Aderhold et $\mathrm{al}^{1}$. Em 68\% dos casos houve um crescimento misto de aeróbios e anaeróbios. Em $28 \%$ houve o crescimento apenas anaeróbio e em 4\% apenas aeróbio. A combinação Streptococcus aeróbios e Bacteroides foi isolada em $60 \%$ dos casos.

Corroborando os estudos anteriores, Von Know et $\mathrm{al}^{22}$ realizaram uma pesquisa em 57 pacientes, portadores de infecções dentoalveolares. Uma média de 4 espécies bacterianas por espécime foi obtida, e apenas $1 / 3$ das espécies eram aeróbias. Entre as bactérias aeróbias, os Streptococcus predominaram e entre os anaeróbios os bacilos Gram-negativos, Bacteroides ruminola, Fusubacterium nucleatum foram mais freqüentemente isolados, seguidos de cocos Gram-positivos, em particular Streptocococcus intermedius.

Durante a década de 80, os trabalhos foram comprovando a importância dos anaeróbios. Brook I et al. ${ }^{5}$ estudando a bacteriologia dos abscessos periapicais agudos em crianças, concluíram que os organismos anaeróbios representam um papel fundamental na etiologia polimicrobiana desses abscessos. Os microrganismos anaeróbios foram isolados em todos os pacientes. No entanto, 8 pacientes $(67 \%)$ apresentaram como flora exclusiva; 4 pacientes $(33 \%)$ apresentaram crescimento misto de anaeróbios e aeróbios. Dos 53 anaeróbios isolados (4.4 por espécime) estavam presentes: 20 espécies de Bacteroides (incluindo 9 Bacteroides melaninogenicus; 3 Bacteroides oralis; e 3 Bacteroides corrodens); 17 cocos anaeróbicos gram positivos; 5 espécies de Fusobacterium e 3 espécies de Actinomyces. Foram isolados 6 aeróbios (5 por espécime): 3 Streptococcus salivarius, 2 estreptococos alfa hemolíticos e 1 estreptococo gama hemolítico. Neste estudo, é citado a importância dos anaeróbios nos abscessos periapicais, pois a partir de um foco dental podem ser originadas infecções como bacteremia, endocardite, sinusite, meningite, empiema subdural, abscesso cerebral e empiema pulmonar.

O predomínio de patógenos anaeróbios, em 50 abscessos orofaciais, foi encontrado por Labriola DJ et $\mathrm{al}^{23}$. Em seus achados, eles verificaram $86 \%$ das espécimes continham 
microrganismos anaeróbios e neste grupo $39 \%$ eram resistentes a penicilina. Os gêneros anaeróbios mais isolados foram os seguintes: Bacteroides, Peptostreptococcus, Fusobacterium e Peptococcus.

A correlação entre sintomas clínicos $\mathrm{e}$ microrganismos isolados de canais radiculares de dentes com patologia periapical também foi estudada por Yoshida $M$ et al ${ }^{41} \mathrm{em} 1987$. Os 36 pacientes do Departamento de Endodontia da Universidade de Osaka, foram divididos em 3 grupos que mostravam combinação de sintomas. Os espécimes do grupo 1 apresentavam dor espontânea, dor à percussão e exsudato, no grupo 2 havia presença de dor à percussão, mas não espontânea e os espécimes do grupo 3 se apresentavam sem dor espontânea, sem exsudato e sem dor à percussão (grupo controle). Os autores sugerem que a falta de sintomas dínicos está relacionada com um número menor de colônias isoladas, quando comparado com dentes onde os sintomas clínicos estavam presentes. Neste estudo, o grupo de dentes que apresentavam dor espontânea, dor a percussão e com exsudato apresentaram mais de $79 \%$ de microrganismos anaeróbios. Entre os anaeróbios, Eubacteriunt, Bacteroides e Peptostreptococcus foram as espécies freqüentemente encontradas. Nos dentes assintomáticos predominaram os anaeróbios facultativos.

Haapasalo $\mathrm{M}^{9}$ fez um relato sobre a bacteriologia de 62 canais radiculares humanos infectados, dando atenção especial às espécies Bacteroides. Os resultados confirmaram as descobertas de investigaçōes anteriores, nos quais quase todas as infecçōes dos canais radiculares sāo mistas e os sintomas agudos estão usualmente relacionados à presença de anaeróbios específicos, tais como Porphyromonas (Bacteroides) gingivalis, Porphyromonas (Bacteroides) endodontalis e Prevotella (Bacteroides) buccae.

No final da década de 80, Sundqvist $G$ et al $\mathbf{1}^{34}$ confirmaram a relevância dos Bacteroides. Em 1989 os autores realizaram um estudo com o objetivo de avaliar a prevalência de espécies de Bacteroides pigmentados com preto em infecçöes do canal radicular. Esse estudo mostrou que os Bacteroides pigmentados de preto estão envolvidos no desenvolvimento de abscessos apicais e que a presença da combinação do $B$. intermedius, $B$ endodontalis ou $B$. gingivalis aumenta o risco de desenvolvimento de uma inflamação apical purulenta.

A bacteriologia dos abscessos periodontais e endodônticos foram comparadas, em 1988, através do estudo de Trope $\mathrm{M}$ et $\mathrm{al}^{39}$. Os autores utilizaram a microscopia de campo escuro como auxiliar no diagnóstico diferencial de exsudatos de abscessos periodontais e endodônticos $\mathrm{e}$ verificaram uma distinta variação no percentual de espiroquetas. Em abscessos periodontais a ocorrência de espiroquetas variou de 30 a $60 \%$, enquanto que em abscessos endodônticos a variaçāo foi de 0 a $10 \%$.

Em 1992, Trope $M$ et $a^{36}$ descreveram dois casos, nos quais a contagem de espiroquetas através da microscopia de campo escuro foi de grande valor na diferenciação dos abscessos periodontais e endodônticos. $\mathrm{O}$ abscesso periodontal teve uma média de $51 \%$ de espiroquetas e o abscesso endodôntico teve uma média de $4,7 \%$ de espiroquetas. Baseado nas conclusões da microscopia de campo escuro o tratamento correto foi instituído e a cura deu-se em ambos os casos.

A década de 90 já inicia com o estudo de Baumgartner ${ }^{16}$ que relatou que a presença de certos organismos, particularmente Bacteroides, Peptostreptococcus e Fusobacterium está associada com um aumento na incidência de alguns sinais e sintomas endodônticos.

Em 1992, com o propósito de investigar a correlação entre a composição bacteriana de canais radiculares infectados e sintomas da necrose pulpar, Hashioka $\mathrm{H}$ et $\mathrm{al}^{19}$ estudaram a flora bacteriana de 28 dentes monorradiculares com periodontite apical aguda. Os resultados indicaram que existe uma relação positiva entre Peptococcus, Peptostreptococcus, Eubacterium, Porphyromonas e Bacteroides isolados do canal radicular e dor à percussão e também foi evidenciada associação de Porphyromonas e Bacteroides com presença de odor fétido.

Ainda em 1992, com o propósito de revisarem a função de Porphyromonas endodontalis em infecçōes dentárias, Van Winkelhoff et $a^{38}$ relataram que tal microrganismo parece estar especificamente envolvido em infecções endodônticas. A $P$. endodontalis apresenta uma grande sensibilidade ao oxigênio atmosférico e isto pode ter contribuído para a baixa taxa de isolamento desta espécie em outros estudos como o de Haapasalo et al $^{38}$ que encontraram $P$. endodontalis em apenas 2 dos 32 casos de dentes com periodontite apical.

Em um estudo feito para associar bactérias específicas com alguns sinais e sintomas endodônticos, Gomes et al ${ }^{15}$ isolaram $93 \%$ de anaeróbios em dentes sintomáticos e apenas $53 \%$ de anaeróbios em dentes assintomáticos. Os resultados do estudo indicaram que existe uma associação significativa entre dor e a presença de Prevotclla e Peptococcus spp. em canais radiculares.

Fischer e Russel ${ }^{30}$ afirmaram que em abscessos dentários, os grupos de Streptococcus Millieri são os microrganismos anaeróbios facultativos mais freqüentemente isolados e preparam o ambiente para o estabelecimento de infecçōes estritamente anaeróbias. Os grupos de Streptococcus millieri também podem agir com sinergismo com bactérias anaeróbias no desenvolvimento de abscessos periapicais.

Brauner et $\mathrm{al}^{4}$ estudou a microbiologia de 19 dentes que apresentavam sintomas clínicos de pulpite e 24 dentes sintomáticos com granuloma periapical. Os microrganismos isolados com maior freqüência foram Prevotella intermedia, Bifidobacterium spp. e Streptococcus sanguis, Streptococcus grupo milleri e Bacteroides spp. Os anaeróbios obrigatórios ocorreram em uma taxa de $82,3 \%$ e a média de microrganismos isolados foi de 6,4 por amostra. Os autores concluíram que são muito similares as amostras isoladas dos dentes com pulpite e dos dentes com granuloma do ponto de vista qualitativo, porém, há uma diferente distribuição quantitativa, sendo a maior prevalência ocorrediça nos casos de granuloma.

Corroborando estudos anteriores, Gomes et al ${ }^{16}$ realizaram um estudo com o propósito de examinar microbiologicamente a mais extensiva série de canais radiculares para determinar se algum sintoma endodôntico ou sinal clínico demonstram uma associação específica com uma espécie bacteriana em particular. Para tanto, os autores examinaram microbiologicamente e coletaram dados clínicos para realizar as associaçōes em 70 canais radiculares. Os autores isolaram $70,3 \%$ de anaeróbios em canais radiculares sintomáticos e apenas $29,7 \% \mathrm{em}$ canais assintomáticos. Associações significativas foram encontradas entre:

a) Dor: Prevotella spp. ou Peptostreptococcus spp.;

b) Sensibilidade à percussão: Prevotella spp ou anaeróbios;

c) Edema: Eubacterium spp. ou com Prevotella spp. ou Peptostreptococcus micros;

d) Exsudato purulento: F: necrophorum ou Prev. Loescheii ou Streptoccoccus constellatus ou Bacteroides spp.;

e) Canal úmido: anaeróbios facultativos e qualquer um dos gêneros: Eubacterium, Peptostreptococcus, Prevotella ou Propionibacterium.

\section{DISCUSSĀO E POSIÇÃO CLÍNICA}

A literatura odontológica é repleta de estudos bacteriológicos das infecçóes endodônticas. Estes apresentam consideráveis variaçōes em seus resultados, dependendo de vários fatores: a) o estado do dente, b) as precauçōes que foram feitas para descontaminar o campo operatório, c) o tipo de coleta, d) o meio de transporte, e) o meio de cultura, f) o tipo de incubação eg) os métodos de identificação laboratorial.

O estudo bacteriológico das infecções endodônticas possui inúmeras dificuldades inerentes. Uma das questões é que a cavidade bucal apresenta como microbiota normal mais de 350 espécies bacterianas, sendo assim a metodologia das pesquisas de infecções pulpares deve garantir o isolamento das bactérias do canal radicular, sem haver contaminação com a microbiota bucal normal. Faz-se necessário o isolamento absoluto do campo operatónio e uma desinfecção prévia do dente e estruturas vizinhas. Com relação à desinfecção inicial, os autores Winkler $\mathrm{KC}$ e Van Amerogen $\mathrm{J}^{40} \mathrm{em}$ 1959 realizavam com $5 \%$ de tintura de iodo. Já Zavistoski et al ${ }^{42}$ utilizaram quatro aplicaçōes de merthiolate seguido de uma lavagem de hipoclorito de sódio a 5,25\%. Em 1987 , Yoshida $\mathrm{M}$ et al ${ }^{41}$ também usaram tintura de iodo. Em 1992, Hashioka H et al ${ }^{19}$ realizaram o procedimento de assepsia com solução de $5 \%$ de iodo etanol e etanol $70 \%$. Gomes et al ${ }^{15}$, em 
1994, usou soluçāo de gluconato de clorexidina a $0,5 \%$ e em 1996 usou digluconato de clorexidina a $0,1 \%$. Esses procedimentos variam de estudo para estudo, mas todos eles concordam com o uso de um antimicrobiano para desinfecção inicial como forma de garantir uma amostra viável.

Outra dificuldade encontrada no estudo das infecções endodônticas é a pequena quantidade de material para cultura. Os estudos são restritos aos fluidos dos canais radiculares que podem ser absorvidos com o uso de pontas de papel absorvente que são inseridas comumente em um caldo para incubação antes da sub-cultura em placas de meio standard. $O$ problema desta técnica é que várias bactérias repicam em diferentes taxas e que organismos que crescem lentamente podem ter um número insignificante quando comparados com organismos de crescimento rápido, podendo aqueles, inclusive, não serem isolados.

Nos casos assintomáticos, os achados com relação ao total de anaeróbios têm variado com o passar dos anos. O trabalho de Yoshida et $\mathrm{al}^{41}$, nos casos clínicos do grupo controle, que não apresentavam dor espontânea, nem exsudato e sem dor à percussão, mostra um predomínio de anaeróbios facultativos $(83,3 \%)$. Já Fukushima ${ }^{13}$ encontrou um predomínio de bactérias anaeróbias, pois foram isoladas $\mathrm{em}$ todos os casos, com exceção apenas de um caso. E em 1994, Gomes et al ${ }^{15}$ isolaram $53 \%$ de anaeróbios em dentes assintomáticos e em 1996, usando a mesma metodologia de 1994, isolaram apenas $29,7 \%$ de anaeróbios.

Por outro lado, nos casos sintomáticos, há uma concordância nos estudos 23.41 .15.4.16 sobre o total de anaeróbios isolados. Os resultados indicam percentuais acima de $79 \%$ de microrganismos anaeróbios do total de isolados.

As espécies Bacteroides, Peptostreptococcus, Peptococcus e Eubacterium são as mais relacionadas com patologias periapicais sintomáticas ${ }^{33,1,22,17,5,23,41,19,16}$. Essas, entre um conjunto de outras espécies bacterianas, podem crescer quando ocorrer a exacerbação de um processo crônico.

A partir da década de 70 , muitos trabalhos referendaram a presença de microbiota anaeróbia específica em infecçōes endodônticas agudas. Os Bacteroides foram os primeiros microrganismos associados e são os mais citados nos estudos $33,1,22,17,5,23,41,19,16$. Seguidos dos Bacteroides, os Peptostreptococcus, também são muito citados em vários estudos ${ }^{33.23,41,19,16}$ como patógenos importantes das infecções endodônticas sintomáticas.

Um exemplo, é o estudo de Labriola DJ et $\mathrm{al}^{23}$ que em seus resultados os gêneros anaeróbios mais isolados foram: a) Bacteroides, b) Peptostreptococcus, c) Fusobacterium e d) Peptococcus.

Confirmando estudos anteriores, Baumgartner ${ }^{16}$ relatou que a presença de certos organismos, particularmente Bacteroides, Peptostreptococcus e Fusobacterium está associada com um aumento na incidência de alguns sinais e sintomas endodonticamente tratáveis.

Em verdade, as infecções endodônticas possuem uma microbiota mista de aeróbios e anaeróbios. Isso foi mostrado, por exemplo, por Zavistoski et $\mathrm{al}^{42} \mathrm{em} 90 \%$ dos casos estudados e por Haapasalo', sendo que este último também relacionou sintomas agudos à presença de anaeróbios específicos tais como Porphyromonas (Bacteroides) gingivalis, Porphyromonas (Bacteroides) endodontalis e Prevotella (Bacteroides) buccae. Outros estudos ilustrando essa premissa são o de Aderhold et al $^{1} \mathrm{em} 1981$ que encontraram a combinação Streptococcus aeróbios e Bacteroides em $60 \%$ dos casos e o de Von Know et al ${ }^{22}$ que também encontraram, entre as bactérias aeróbias, o predomínio de Streptococcus, e entre os anaeróbios, os bacilos Gram-negativos, Bacteroides ruminola, Fusubacterium nucleatum foram mais freqüentemente isolados, seguidos de cocos Gram-positivos, em particular Streptococcus intermedius.

Corroborando estudos anteriores, a presença de bactérias aeróbias e anaeróbias foi encontrada no estudo de Brook I et $\mathrm{al}^{5}$. Dos 53 anaeróbios isolados (4.4 por espécime) estavam presentes: 20 espécies de Bacteroides (incluindo 9 Bacteroides melaninogenicus; 3 Bacteroides oralis; e 3 Bacteroides corrodens); 17 cocos anaeróbicos gram positivos; 5 espécies de Fusobacterium 3 espécies de Actinomyces. Foram isolados 6 aeróbios (5 por espécime): 3 Streptococcus salivarius, 2 estreptococos alfa hemolíticos e l estreptococo gama hemolítico.

Diante dessas constatações, verificamos que é indiscutível a prevalência de microrganismos anaeróbios em infecções agudas endodônticas. Acreditamos, baseados na literatura, que os anaeróbios são habitantes sinérgicos com a microbiota aeróbia.

As pesquisas microbiológicas contribuíram muito para o desenvolvimento da técnica endodôntica. Atualmente, sabe-se que o canal radicular deve ser preparado adequadamente, em toda a sua extensão, através da combinação de manobras e processos mecânicos da instrumentação, pela irrigação com substância bactericida, e pelo uso de medicação intra-canal. Completa-se o tratamento endodôntico, após o saneamento obtido, com a obturação hermética do canal radicular.

Apesar de alguns profissionais da atualidade abolirem a etapa de medicação intracanal da sua rotina clínica, a evidência apresentada da prevalência dos microrganismos anaeróbios nas patologias de periápice reforça a necessidade de fazermos tal manobra intermediária. Sendo assim, recomendamos que na atividade de clínica geral a etapa da medicação intra-canal não seja facultativa, mas obrigatória, principalmente nas patologias periapicais agudas.

O conhecimento da microbiologia endodôntica fundamenta medidas terapêuticas mais efetivas, especialmente em casos onde as manobras convencionais da terapia do ca: radicular não forem eficientes. Na maicr das vezes, estes são os casos de sintomatolc: persistente, em que o paciente já fez uso analgésicos fortes, penicilinas em diver apresentações e o quadro se mantém inaltera: Portanto, indicamos nesses casos, junto manobras locais, a utilizaçāo antimicrobianos eficientes $p=$ microrganismos anaeróbios. O metronidaz tem seu uso na profilaxia e tratamento $c$ infecções causadas por bactérias anaerób. como Bacteroides fragilis e outros Bacteroi. Fusobacterium spp., Clostridium spp., e ca: anaeróbios. $\mathrm{O}$ uso de antimicrobianos t: metronidazol serve como coadjuva: terapêutico às medidas locais em infeç̧:agudas resistentes às manobras convencior:

\section{SUMMARY}

A deep knowledge about endodor: microbiology is a fundamental resource understand the role of bacteria in the or: and development of periapical pathosis as $\mathrm{m}^{\mathrm{a}}$ as dealing with the tissue response to infecti Thus, our purpose of reviewing the literat= about endodontic microbiology is to res: which bacteria are more frequently relatec necrotic dental pulps in order to provi: information which may give support to $\mathrm{mrm}$ adequate methods to eliminate and control sinfection.

\section{KEYWORDS}

Endodontic Infection, Endodo: Bacteriology, Dental Root Canal Infection

\section{REFERÊNCLAS BIBLIOGRÁFICAS:}

1. ADERHOLD, L.; KNOTHE, H.; FRENKEL The bacteriology of dentogenous pyogen infections. Oral Surg. Oral Med. Oral Path St. Louis, v.52, n.6, p.583-87, Dec. 1981

2. ASSED, S.; INTO, IY.; LEONARDO, M.R. e Anaerobic microorganisms in root canals of husa teeth with chronic apical periodontitis detecte: indirect immunofluorescence. Endod. De Traumatol., Copenhagen, v. 12, n.2, p.66-9. 1996.

3. BERGENHOLTZ, G. Micro-organisms from neor: pulp of traumatized teeth Odontol. Rev., Mtim v.25, n.4, p.347-58, Nov. 1974

4. BRAUNER, A.W: CONRADS, G. Studies int microbial spectrum of apical periodontitis in Endod. J., London, v.28, n.5, p.244-48, se 1995.

5. BROOK, I.; GRIM, S.; KIELICH, R.B. Bactering of acute periapical abscess in children. J. End Baltimore, v.7, n.8, p.378-80, Aug. 1981

6. BURKE,G.W.J.; KNIGHTON, H.T. 7t localization of microorganisms in inflaned pulps of rats following bacteremia. Washington, v.39, n.2, p.205-14, Mar/Ape

7. CARLSSON, I; FRÖLANDER, F; SUNDC G. Oxygen tolerance of anaerobic bacteria swame from necrotic dental pulps. Acta Odontol son. Oslo, v.35, n.3, p.139.45, 1977 
8. CARLSSON, J.; SUNDQVIST, G. Evaluation of methods of transport and cultivation of bacterial specimens from infected dental root canals. Oral Surg. Oral Med. Oral Pathol., St. Louis, v.49, n.5, p.451-54, May, 1980.

9. COHEN, S.; BURNS, R. C. Caminhos da polpa. 6.ed. Rio de Janeiro: Guanabara Koogan, 1997. 759p.

10. DAHLÉN, G.; FABRICIUS, L.; HEYDEN, G.; et. al. Apical periodontitis induceded by selected bacterial strains in root canals of immunized and non-immunized monkeys. Scand. J. Dent. Res., Copenhagen, v.90, n.3, p. 207-16, June, 1982.

11. DELIVANIS, P.D.; FAN, V.S.C. The localization of blood-borne bacteria in instrumented unfilled end overinstrumented canals. J. Endod., Baltimore, v. 10, n. I1, p.52 I.24, Nov. 1984.

12. ENGSTRÖM, B; FROSTELL, G. Bacteriological studies of the non-vital pulp in cases with intact pulp cavities. Acta. Odontol. Scand., Oslo, v.19, p.23-9, May, 1961.

13. FUKUSHIMA, H; YAMAMOTO, K; HIROHATA, $K$.; et.al. Localization and identification of root canal bacteria in clinically asymptomatic periapical pathosis. J. Endod., Baltimore, v.16, n.11, p.534-38, Nov. 1990.

14. GIER, R.E.; MITCHEL, D.F, Anachoretic effect of pulpitis. J. Dent. Res., Washington, v.47, n.4, 564-70, July/Aug. 1968

15. GOMES, B.P.F.A.; DRUCKER, D.B.; LILLEY, J.O Association of specific bacteria with some endodontic signs and symptoms. Int. Endod. I., London, v.27, n.6, p.291-98, Nov. 1994.

16. GOMES, B.P.F.A.; LLLLEY, J.D.; DRUCKER, D.B Clinical significance of dental root canal microflora. J. Dent., Surrey, v.24, n.1-2, p.47.55 Jan/Mar., 1996.

17. GRIFFEE, M.B.; PATTERSON, S.S.; MILLER, C.H. et al. The relationship of Bactcroides melaninogenicus to symptoms associated with pulpal necrosis. Oral Surg. Oral Med. Oral Pathol., St. Louis, v.50, n.5, p.457-61, Nov. 1980.

18. GROSSMAN, L.I. Origin of microorganisms in traumatized, pulpless, sound teeth. J. Dent. Res. Washington, v.46, n.3. p.551-53, June, 1967.

19. HASHIOKA, K; YAMASAKI, M.; NAKANE, A. et al. The relationship between clinical symptoms and anaerobic bacteria from infected root canals. J. Endod., Baltimore, v.18, n.11, p.558-61, Nov. 1992.

20. KAKEHASHI, S.; STANLEY, H.R.; FITZGERALD, R.J. The effects of surgical exposures of dental pulps in germ-free and conventional laboratory rats. Oral Surg. Oral Med. Oral Pathol. St Louis, v.20, n.3, p.340-49, Sept. 1965.

21 KANTZ, WE: HENRY C.A Isolation and classification of anaerobic bacteria from intact pulp chambers of non vital teeth in man. Arch. Oral Biol., Oxford, v.19, n.1, p.91-6, Jan/June. 1974

22. KONOW, L.V.; NORD, E.C.; NORDENRAM, A Anaerobic bacteria in dentoalveolar infections. Int. J. Oral Surg., Copenhagen, v. 10, n.5, p.313 22 , Oct. 1981
23. LABRIOLA, J.D; MASCARO, J.; ALPERT, B. The microbiologic flora of orofacial abscesses. J. Oral Maxilofac. Surg., v.41, n.II, p.711-14, Nov. 1983.

24. MACDONALD, J.B.; HARE, G.C.; WOOD, A.W.S The bacteriologic status of the pulp chambers in intact teeth found to be nonvital following trauma. Oral Surg. Oral Med. Oral Pathol., St. Louis, v.10, n.3, p.318-22, Mar. 1957.

25. MÖLLER, A.J.R.; FABRICIUS, L.; DAHLÉN, G. et al. Influence on periapical tissues of indigenous oral bacteria and necrotic pulp tissue in monkeys. Scand. J. Dent. Res., Copenhagen, v.89, n.6, p.475-84, Dec. 1981

26. NAIR, P.N.R. Apical periodontitis: a dynamic encounter between root canal infection and host response. Periodontol. 2000, Copenhagen, v. 13 , p. $121-46,1997$.

27. NAIR, R. Light and electron microscopic studies of root canal flora and periapical lesions. I. Endod. Baltimore, v.13, n.1, p. 29-39, Jan. 1987.

28. PETERS, LB - WESSELINK, PR.; MOORER, W.R. The fate and the role of bacteria left in root dentinal tubules. Int. Endod. J., London, v.28, n.2, p.959. Mar. 1995.

29. ROBINSON, H.B.G.; BOLING, L.R. The Anachoretic effect of pulpitis. Bacteriologic studies. J. Am. Dent. Assoc, Chicago, v.28, n. 1, p.26882, Feb. 1941

30. SELTZER, S.; FARBER, P.A. Microbiologic factors in endodontology. Oral Surg. Oral Med. Oral Pathol., St. Louis, v.78, n.5, p.634-45, Nov. 1994.

31. SIQUEIRA Ir, J.F; UZEDA De, M.; FONSECA M.E.F. A scanning electron microscopic dentinal tubules penetration by selected anaerobic bacteria. J. Endod., Baltimore, v.22, n.6, p.308-10, June, 1996.

32. SUNDQVIST, G. Associations between microbial species in dental root canal infections. Oral Microbaiol. Immunol., Copenhagen, v.7, n.5, p.257-62, Oct. 1992

33. SUNDQVIST, G.; ECKERBOM, M.I.; LARSSON A.P. et al. Capacity of anaerobia bacteria from necrotic dental pulps to induce purulent infections. Infect. Immun., Washington, v.25, n.2, p.68593, Aug. 1979.

34. SUNDQVIST, G.; JOHANSSON, E.; SJÖGREN, U. Prevalence of black-pigmented Bacteroides species in root canal infections. J. Endod. Baltimore, v. 15, n.1, p.13.9, Jan. 1989.

35. THILO, E.B.; BAEHNI, P.; HOLTZ, J. Dark-field observation of the bacterial distribution in root canals following pulp necrosis. J. Endod. Baltimore, v.12, n.5, p.202-05, May, 1986.

36. TROPE, M.; ROSEMBERG, E; TRONSTAD, L Darkfield microscopic spirochete count in the differentiation of endodontic and periodontal abscesses. J. Endod, Baltimore, v.18, n.2, p.826, Fev. 1992.

37. TROPE, M.; TRONSTAD, L.; ROSEMBERG, E. et al. Darkfield microscopy as a diagnostic aid in differentiating exudates from endodontic and periodontal abscesses. J. Endod., Baltimore, v.14 n. 1, p.35-8, Jan. 1988 .
38. VAN WINKELHOFF, A.J.; VAN STEENBERGEN, TJ M. GRAFF, J Porphyromonas (bacteroides) endodontalis: its role in endodontal infections. J. Endod, Baltimore, v.18, n.9, p.431-34. Sept. 1992.

39. WALTON, R.E.; TORABINEJAD, J. Principios e prática em endodontia. São Paulo:Santos, 1997. $558 \mathrm{p}$.

40. WINKLER, K.C.; VAN AMEROGEN, J. Bacteriologic results from 4,000 root canal cultures. Oral Surg. Oral Med. Oral Pathol., St. Louis v. 12, n.7, p.857-1123, July, 1959.

41. YOSHIDA, M.; FUKUSHIMA, H.; YAMOTO, K et al. Correlation between clinical symptoms and microorganisms isolated from root canals of teeth with periapical pathosis. J. Endod, Baltimore, v. 13, n. I, p.24-8, Jan. 1987

42. ZAVISTOSKI, J.; DZINK, J.; ONDERDONK, A. et al. Quantitative bacteriology of endodontic infections. Oral Surg. Oral Med Oral Pathol. St. Louis, v.49, n.2, p.171-74, Feb. 1980. 